\title{
Pregnancy Outcome of Single Previous cesarean Section
}

\author{
Jha $M^{1}$ \\ ${ }^{1}$ Paropkar Maternity \& Women Hospital, Kathmandu, Nepal
}

\begin{abstract}
Background: The main aim of this study is to determine the maternal and fetal outcome of pregnancy among women with one previous caesarean section at term in relation to vaginal delivery, post partum complication, neonatal complication like low Apgar score, fetal weight and admission in special baby unit.

Methods: This is a prospective and descriptive study done in a sample size of 100. Inclusion criteria were term pregnancy, single live fetus with cephalic presentation with one previous caesarean section. During study period total number of obstetric admissions was 3546 and 115 cases were admitted with previous one caesarean section.

Result: Out of 100 cases, 31 cases had vaginal delivery and 69 cases had caesarean section. Among 31 vaginal deliveries, 24 cases had spontaneous vaginal delivery and 7 had assisted delivery with vacuum, main indication of vacuum delivery was to cut short the second stage of labor that was in $5(71.43 \%)$ cases.

Among 69 caesarean section cases, 51 had emergency caesarean section and 18 had elective caesarean section and cephalopelvic disproportion was the main indication in both the groups. Most common complication was scar dehiscence and postpartum hemorrhage. There were two still births in each group and one minute APGAR score was slightly better in caesarean section.

Conclusions: Patients with previous caesarean section are at high risk of repeat emergency or elective caesarean section. About one in three patients with previous caesarean section delivered vaginally. In the present study postpartum hemorrhage was the commonest complication, which was found in caesarean section, and only one puerperal pyrexia was seen in case of vaginal delivery.

Key words: Cephalopelvic disproportion, Premature rupture of membrane, Septicemia, Vacuum delivery
\end{abstract}

\section{INTRODUCTION}

It is hoped that by promoting vaginal birth after caesarean section, we will reduce the incidence of caesarean section. The term “caesarean” for abdominal delivery of a child by cutting through the abdominal wall and the uterus is believed to be derived from Greek word "lex regia" which later became known as "lex caesaria". 1 Caesarean section may be life saving for the baby, or the mother. ${ }^{2}$

Correspondence: Dr. Meena Jha, Paropkar Maternity \& Women Hospital, Kathmandu, Nepal. Phone: 9851055673, Email: drmeenajha@yahoo.com 
Pregnancy Outcome of Single Previous cesarean Section

In USA the rate of caesarean has risen in the past twenty years to a rate of approximately $20 \%$ to $25 \%{ }^{3}$ A study shows that $63 \%$ of women delivered vaginally whose previous caesarean section was done for cephalopelvic disproportion or non progress of labor. Trial of labor should be encouraged after a previous caesarean section provided that there is no absolute contraindication of vaginal birth such as placenta praevia and pelvic contraction. ${ }^{4} \mathrm{~A}$ patient with caesarean section is at high risk and poses a challenging problem to the obstetrician. Craigins dictum "Once a caesarean section always a caesarean section" has now been modified into "Once a caesarean section always a hospital delivery." ${ }^{5}$

This study was done to determine the maternal and fetal outcome of pregnancy with previous one caesarean section, to estimate the rate of vaginal delivery and repeat caesarean section, to study the indication of repeat caesarean section and to study the maternal complication and fetal outcome in terms of Apgar score, fetal weight, fetal morbidity and mortality.

\section{METHODS}

It was a prospective study conducted at Maternity Hospital, Thapathali, Kathamand for a period of three months from February 23 to April 28, 2005. Data was collected every day of the week, except Saturday from the admission room. The enrolling criteria were term pregnancy with one previous caesarean section, cephalic presentation and single live fetus. The gestational age was confirmed by the last menstrual period (LMP) and ultrasonography in patients who did not remember or were unsure of date. This was followed by general, abdominal and vaginal examination to confirm that the patient fulfilled the criteria to be enrolled in the study. Maternal outcome in terms of mode of delivery and postpartum maternal morbidity like postpartum hemorrhage, injury to the genital tract, genital tract infection, urinary tract infection, pyrexia, wound dehiscence were noted. Fetal outcome was measured in terms of fetal heart rate, me conium stained liquor, Apgar score, still birth and admission in the neonatal intensive care unit, birth weight.

Permission was taken from hospital authority and the consultant of each unit. Verbal and written consent was taken by the patients before preceding the study.

After collection of all the data they were analyzed and results presented in table and graph. Final statistical analysis of the data was done by using EPI-INFO-6 program.

\section{RESULT}

Out of the 100 study cases, $31 \%$ had vaginal deliveries as shown in (Fig-1). Among the vaginal delivery, 24 were spontaneous vaginal delivery while 7 were assisted with vacuum. Main indication of vacuum delivery was to cut short the second stage of labor that was in five cases (71.43\%).

In the age group 25-29 yrs vaginal delivery cases were $11(35.48 \%)$ and caesarean section was 34(49.28\%). The caesarean section was slightly higher in the same age group. But this difference was not statistically significant. $P=0.891$. Majority of patients were of $37-$ 39 wks of gestation. In this gestational age group $17(54.83 \%)$ had vaginal delivery and $36(52.17 \%)$ had caesarean section. But this difference was not statistically significant. Among 69 caesarean sections, $51(73.91 \%)$ had emergency caesarean sections and $18(26.08 \%)$ had elective caesarean sections. The repeat caesarean section is also high whose previous caesarean section was done for fetal distress (Table-1). The most common indication of repeat caesarean section in both groups (elective and emergency) were cephalopelvic disproportion in emergency caesarean section $49.01 \%$ and in elective caesarean section $88.88 \%$. (Table-2).

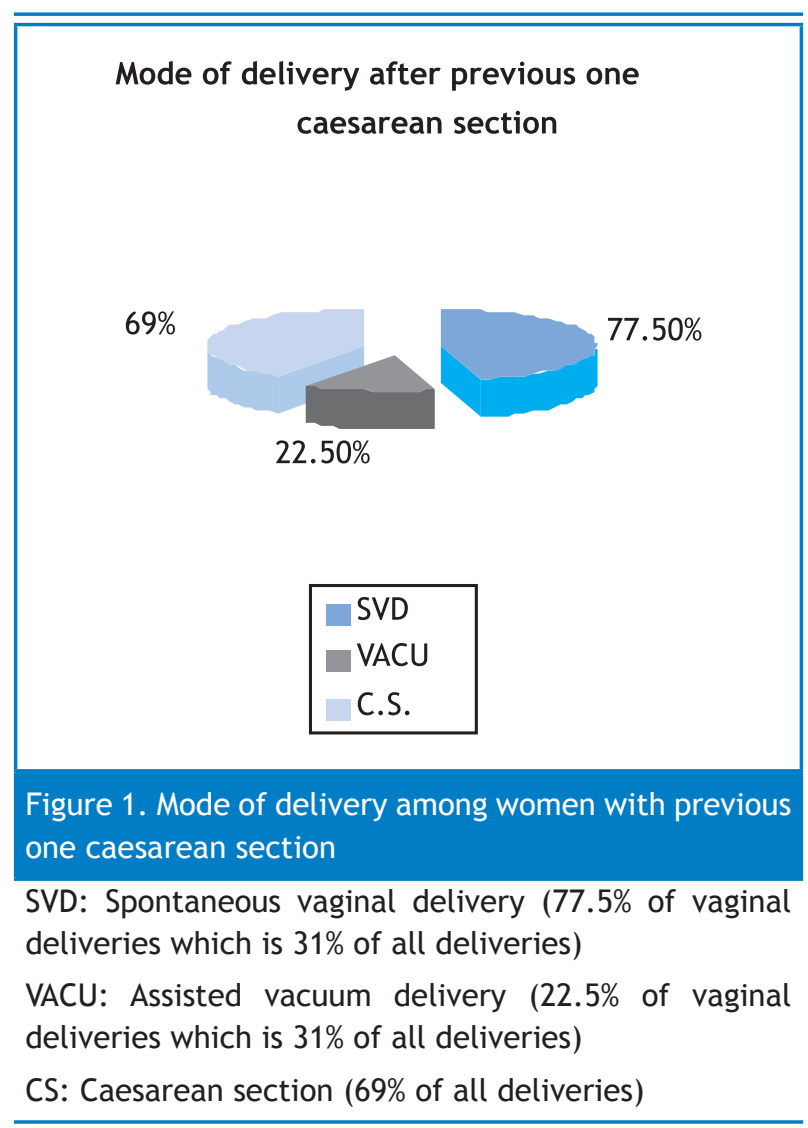


Pregnancy Outcome of Single Previous cesarean Section

Table 1. Indication of previous caesarean section and mode of delivery in the index pregnancy

\begin{tabular}{|c|c|c|c|c|c|c|}
\hline \multirow[t]{2}{*}{ Indication of previous caesarean section } & \multicolumn{2}{|c|}{$\begin{array}{l}\text { Normal delivery } \\
\qquad n=24\end{array}$} & \multicolumn{2}{|c|}{$\begin{array}{l}\text { Instrumental } \\
\text { Delivery } n=7\end{array}$} & \multicolumn{2}{|c|}{$\begin{array}{c}\text { Caesarean } \\
\text { section } n=69\end{array}$} \\
\hline & no & $\%$ & no & $\%$ & no & $\%$ \\
\hline Fetal distress & 6 & 25.04 & 1 & 14.28 & 14 & 20.28 \\
\hline Breech & 4 & 16.66 & 1 & 14.28 & 8 & 11.59 \\
\hline Cephalo pelvic disproportion & 2 & 8.33 & 0 & 0 & 13 & 18.84 \\
\hline Non progress of labour & 2 & 8.33 & 1 & 14.28 & 5 & 7.24 \\
\hline Antepartum haemorrhage & 4 & 16.66 & 0 & 0 & 6 & 8.69 \\
\hline Transverse lie & 0 & 0 & 0 & 0 & 5 & 7.24 \\
\hline Failed Induction & 1 & 4.16 & 2 & 28.57 & 8 & 11.59 \\
\hline Severe pre-eclampsia & 0 & 0 & 1 & 14.28 & 0 & 0 \\
\hline Obstructed labour & 0 & 0 & 1 & 14.28 & 0 & 0 \\
\hline Intrauterine growth retardation & 2 & 8.33 & 0 & 0 & 0 & 0 \\
\hline Prolong pregnancy & 1 & 4.16 & 0 & 0 & 0 & 0 \\
\hline Cord prolapse & 0 & 0 & 0 & 0 & 2 & 2.8 \\
\hline Oligohydramnios & 0 & 0 & 0 & 0 & 1 & 1.4 \\
\hline Anencephaly & 0 & 0 & 0 & 0 & 1 & 1.4 \\
\hline Not known & 2 & 8.33 & 0 & 0 & 6 & 8.69 \\
\hline Total & 24 & 100 & 7 & 100 & 69 & 100 \\
\hline
\end{tabular}

Table 2. Analysis of indication of repeat caesarean section in the index pregnancy

\begin{tabular}{|c|c|c|c|c|}
\hline \multirow[t]{2}{*}{$\begin{array}{l}\text { Indication of repeat caesarean } \\
\text { section }\end{array}$} & \multicolumn{2}{|c|}{$\begin{array}{l}\text { Emergency caesarean section } \\
\qquad n=51\end{array}$} & \multicolumn{2}{|c|}{$\begin{array}{l}\text { Elective caesarean section } \\
\qquad n=18\end{array}$} \\
\hline & no & $\%$ & no & $\%$ \\
\hline Cephalopelvic disproportion & 25 & 49.01 & 16 & 88.88 \\
\hline Non progress of labour & 10 & 19.61 & 0 & 0 \\
\hline Prolong pregnancy & 2 & 3.93 & 1 & 5.56 \\
\hline Scar tenderness & 14 & 27.45 & 1 & 5.56 \\
\hline Total & 51 & 100 & 18 & 100 \\
\hline
\end{tabular}

Out of 69 cases of repeat caesarean section most common indication of repeat caesarean section was cephalopelvic disproportion in both the groups. This is statistically significant $\mathrm{P}=0.01$.

Maternal morbidity was seen in nine cases in which postpartum hemorrhage was the commonest complication. Five cases of the postpartum hemorrhage were due to extension of angle in cesarean section done for CPD and only one puerperal pyrexia was seen in case of vaginal deliveries.

One minute Apgar score is slightly better in caesarean section that is $>7$ among $60 \%$ of cases, but it is statistically not significant. The total neonatal admission was 24 in which nine were in the vaginal delivery group and 15 in the caesarean section group, six of the caesarean delivery neonatal admission were due to septicemia. Caesarean section done for non progress of labor and premature rupture of membrane baby had increased incidence of septicemia.

\section{DISCUSSION}

Vaginal birth after caesarean section has been advocated as a safe and practical means of reducing the overall caesarean delivery rate. More than 20,000 women with a history of caesarean delivery undergoing a trial of labor have been studied with successful vaginal delivery rate ranging from $50 \%$ to $80 \% .{ }^{6}$ In October 26,1998 the American College of Obstetrician and Gynecologist updated there guidelines concerning vaginal delivery 
Pregnancy Outcome of Single Previous cesarean Section

after previous caesarean section. The committee on obstetrics, maternal, fetal medicine stated that "the concept of routine repeat caesarean birth should be replaced by specific indication for subsequent abdominal delivery and in the absence of a contraindication, a woman with one previous caesarean delivery, with low transverse incision should be counseled and encouraged to attempt labor in her current pregnancy."

In the Maternity Hospital, Thapathali, trial of labor is given after one previous caesarean section, if there is no recurrent indication for previous caesarean section but for women with previous two caesarean sections, routine elective caesarean section is done.

Incidence of vaginal delivery after previous one caesarean section was $31 \%$ which is very much less than $70 \%$ reported as by Jones et all, 1991 USA. ${ }^{8}$

A study shows the incidence of forceps delivery to be about $6 \%$ of all women delivered vaginally and vacuum extraction was used in $5 \%$ of vaginal delivery. ${ }^{9}$

In the present study there was no forceps delivery and incidence of vacuum delivery was $22.5 \%$. In the present study CPD clinical diagnosis was made by senior obstetrician, X- ray pelvimetry was not done. Patients with duration of labor more than 24 hours had 3.5 times more risk of developing post operative complication than patient with labor pain less than 12 hours. ${ }^{10}$ One study showed that risk of scar dehiscence was more among misoprost and induction of labor with oxytocin. ${ }^{11}$ Retrospective data shows risk of scar dehiscence was 2.5\% who had taken vaginal prostaglandin. ${ }^{12}$ In the Maternity Hospital Thapathali induction of labor is not performed in patient with history of previous caesarean section but augmentation of labor with oxytocin is judiciously performed in selected cases of previous one caesarean section. In the present study scar dehiscence was seen in seven cases, in which six scar dehiscence were seen in patients with trial of labor and baby was bigger than $3.5 \mathrm{~kg}$ delivered by emergency cesarean section. Birth weight more than $4 \mathrm{~kg}$ was associated with four fold higher risk of caesarean section, finding similar to that of present study. ${ }^{13}$ A study shows that $5 \%$ of the babies whose birth weight was more than $2.5 \mathrm{~kg}$ was admitted in NICU. ${ }^{14}$ Whereas in the present study $2 \%$ of the babies with similar birth weights were admitted in the neonatal care unit.

There was no maternal death during study period.

\section{CONCLUSION}

Patients with previous cesarean section are at high risk of repeat caesarean section. About one in three patients with previous cesarean section delivered vaginally. If trial of labor is allowed under careful patient selection and supervision, the rate of vaginal delivery after caesarean section can be increased safely.

\section{REFERENCE}

1. Meehan FP, Rafia NM, Bolaji IJ. Delivery following previous caesarean section. In: Studd J, editor. Progress in Obst and Gyn. London: Churchill Livingstone; 1993. P. 213-28.

2. Thomas M, Khan GQ. Outcome of pregnancy in patients with one previous LSCS. J Obstet Gynecol 1994;14:416-9.

3. Dickinson JE. Previous caesarean section. In James DK, Weiner CP, Gonik B, ed. High risk pregnancy. 2nd ed. London; W.B.Saunders; 1999. P. $1205-12$

4. Nwokoro CA, Njokanma OF, Orebamjo T, Okeke GC. Vaginal birth after primary cesarean section: the fetal size factor. J Obstet Gynaecol. 2003 Jul;23(4):392-3.

5. Cunningham FG, Gant NF, Leveno KJ, Gilstrap III LC, Hauth JC, Wenstrom KD, editors. Caesarean delivery and postpartum hysterectomy. In: William Obstetric $21^{\text {st }}$ ed. New York: Mcgraw Hill; 1997. P. 538-53.

6. Zelop CM, Shipp TD, Repke JT, Cohen A, Caughey AB et al. Uterine rupture during induced or augmented labor in gravid women with one prior caesarean delivery. Am J Obstet Gynecol 1999; 181:882-6.

7. Joseph GF, Stedman CM, Robichaux AG. Vaginal birth after caesarean section: The impact of patient resistance to a trial of labor. Am J Obstet Gynecol 1991;164:1441-7.

8. Alamia V, Meyer BA, SelioutskI O, Vohra N. Can a VABAC scoring system predict uterine rupture in patients attempting a trial of labour? Journal of Obst and Gyn 1999;94:64.

9. Sing, Justin CW, Haloob RK. An audit on trends of vaginal delivery after one previous caesarean section. Journal of Obst and Gyn 2004;24:135-8.

10. Kumar A, Thakur S, Premi HK, Gupta KB, Randhawa I, et al. Maternal complication in caesarean section deliveries. Journal of Obstetrics and Gynaecology of India 2003;1:36-38.

11. Wing DA, Lovett K, Paul RH. Disruption of prior uterine incision following Misoprostol for labour induction in women with previous caesarean delivery. Obstet Gynecol 1998;91:828-30.

12. Emmons SL, Krohn M, Jackson M, Eschenbach DA. Development of wound infection among women undergoing caesarean section. Am J Infect control 1984;12:19-25.

13. Ilesanmi AO, Odukogbe A, Olaleye DO. Vaginal delivery after one caesarean section in Nigerian women. Journal of Obst and Gyn 1997; 17:139-42.

14. Ziade SM, Abu-Heija AT. Reducing caesarean section rates and perinatal mortality. Journal of Obst and Gyn 1995;15:171-3. 